\title{
The Long Road to Quality-Assured, Moisture Safe Retrofit in the UK
}

\author{
Peter Rickaby \\ UK Centre for Moisture in Buildings, University College London, UK.
}

\begin{abstract}
This keynote presentation tells the story of how a series of catastrophic retrofit failures led to the development of the UK's domestic retrofit quality assurance system. The system was catalysed by the Each Home Counts review and underpinned by knowledge gained from the Retrofit for the Future programme, including the lessons that most retrofit risks are moisture-related, that retrofit goes wrong at corners, junctions, edges and interfaces, and that ventilation is critical to successful retrofit but is poorly understood. The retrofit standard PAS 2035 and the key role of the Retrofit Coordinator in that standard, are both described.
\end{abstract}

Peer-review under the responsibility of the organizing committee of the ICMB21.

Keywords: retrofit; retrofit failures; retrofit standards; retrofit quality assurance.

\section{Introduction}

In Glasgow, Scotland on a stormy night in 2014, four tonnes of external wall insulation (EWI) fell from the top storeys of a residential tower block. The following day, during the same storm, at a primary school in Edinburgh the brick outer leaf of an insulated gable collapsed. These incidents were not isolated examples of failure.

A year earlier, in Preston, nearly three hundred terraced houses were insulated with EWI. No assessments were made of the homes, no designs were prepared, untrained and incompetent installers bodged the job, and there was no quality control. Soon rain penetrated behind the insulation and appeared internally as damp. Eight years later, over two hundred households are still waiting for remediation of damp homes that they cannot not sell.

There are other examples of failed EWI, and several thousand cases of failures where cavity wall insulation (CWI) was installed where it should not have been. The culmination of this catalogue of failures occurred in London on 14 July 2017 , when a cladding fire at Grenfell Tower killed 72 residents, injured 70 more and left over two hundred people homeless. The block had recently been retrofitted with EWI and over-cladding. All of these disastrous failures could have been avoided.

\section{Retrofit for the Future}

Between 2009 and 2014, the Retrofit for the Future programme, funded the retrofit of 115 occupied houses owned by 86 housing associations. The aim was to learn about deep retrofit of domestic buildings. The target was to reduce carbon dioxide emissions to not more than $17 \mathrm{kgCO}_{2} / \mathrm{m}^{2} / \mathrm{yr}$. All of the projects involved improvements to the building fabric and the building services, and the installation of renewable energy systems. The projects were subjected to post-construction review, post occupancy evaluation, monitoring of performance, and academic evaluation. An expert technical panel reviewed all the data and reported their conclusions [1].

Only a few of the Retrofit for the Future projects achieved the performance target, but many lessons were learned about the risks associated with retrofit, how to manage them, and what good practice looks like. Four key lessons stood out.

First, the places where retrofit goes wrong are corners, junctions, edges and interfaces. That is, places where building elements connect with each other and where, without careful detailing, thermal bridging, thermal by-pass and air infiltration and air leakage will occur; and interfaces between the building fabric, the building services and people, where matched capacities and effective controls are important.

Second, the critical role of ventilation in retrofit, in securing healthy indoor air quality when air infiltration rates are reduced, is not well understood by consultants, contractors, installers, landlords or householders.

Third, retrofit involves technical risk, which can be assessed and managed. Most retrofit risks are associated in some way with moisture, so moisture risk management is critical.

Fourth, the 'performance gap' in retrofit, i.e. the difference between predicted and actual savings in fuel use, fuel costs and emissions, is better characterised as an 'attention to detail deficit'. Paying attention to detail goes a long way towards closing the performance gap. 


\section{ICMB21}

\section{The Green Deal and ECO}

At the same time that we were learning from Retrofit for the Future, the UK Government was developing its retrofit programmes - the Green Deal and the Energy Company Obligation (ECO). The Green Deal subsequently failed, but the ECO is expected to remain in place until 2024 and has delivered thousands of energy efficiency measures in UK homes. In neither scheme was there a role for professionals - only for installers.

\section{Each Home Counts}

In the face of mounting retrofit problems, in July 2015 the Government initiated the industry-led Each Home Counts review of consumer advice, protection, standards and enforcement for energy efficiency and renewable energy'. The aim was to restore the confidence of Government, funding bodies and the public in the domestic retrofit industry. The report of the review, which was published in December 2016 [2], included 27 recommendations. An Implementation Board was established to put them into effect.

Three key recommendations of the Each Home Counts review are worthy of note. First, domestic retrofit should move away from a measures-based approach towards a 'whole dwelling' approach. This was seen as the best way of ensuring that appropriate attention is given to corners, junctions, edges and interfaces.

Second, a 'Quality Mark' should be established to identify retrofit work that complies with appropriate standards. The role of the Quality Mark was subsequently entrusted to TrustMark, a consumer standards body. The Government subsequently made the delivery of publicly funded or publicly endorsed retrofit programmes such as ECO subject to TrustMark approval.

Third, a Code of Practice for retrofit, in the form of a framework of technical standards, should be established. The development of the Code of Practice was entrusted to the BSI Retrofit Standards Task Group (RSTG), which is a group of technical experts, most of whom had been involved in Retrofit for the Future.

\section{The BSI Retrofit Standards Framework and PAS 2035}

The BSI Retrofit Standards Framework was subsequently established to bring the best existing standards together and fill gaps. At its heart is a new Publicly Available Specification, PAS 2035:2019 [3]. This is the UK's domestic retrofit standard, published in June 2019, covering the assessment of dwellings for retrofit, improvement option evaluation, the development of medium-term improvement plans, the design and specification of retrofit, and evaluation of the outcomes of retrofit projects.

PAS 2035 is risk based: projects follow one of three paths through the retrofit process according to the outcome of an initial risk assessment. Retrofit designs prepared under PAS 2035 must be based on whole-dwelling assessments covering the context, condition, occupancy, energy performance, ventilation and historical significance of the buildings. Designs must include: construction details for key corners, junctions and edges; compatible specifications for elements that interact; ventilation upgrades; measures to minimise overheating risk; and careful management of moisture risks. The key PAS 2035 retrofit role is the Retrofit Coordinator, which every project must have, and who coordinates projects from inception to evaluation, protects the client's interest and the public interest, and claims compliance with PAS 2035 by submitting evidence to TrustMark.

An important feature of PAS 2035 is that it requires compliance with many of the other standards that are part of the BSI Retrofit Standards Framework, thus ensuring that all current best practice standards are brought to bear. The RSTG continues to develop new standards to expand and complete the framework.

\section{Quality Assurance}

TrustMark and the BSI Retrofit Standards Framework, including PAS 2035, constitute the UK's domestic retrofit quality assurance system. This system has been applied to all Government-funded or endorsed domestic retrofit programmes from July 2021. The transition from unsatisfactory ways of working to TrustMark approval and compliance with PAS 2035 is proving painful for the energy efficiency industry. However, almost everyone engaged in the Each Home Counts review and its implementation is confident that the costs associated with the new quality assurance regime are far outweighed by the cost of continuing to get retrofit wrong.

\section{References}

[1] Retrofit for the Future: Reducing energy use in existing homes - a guide to making retrofit work, Technology Strategy Board, Swindon, 2014.

[2] Bonfield, P., Each Home Counts: An independent review of consumer advice, protection, standards and enforcement for energy efficiency and renewable energy, Department for Business, Energy and Industrial Strategy and Department for Communities and Local Government, London, 2016.

[3] Retrofitting dwellings for improved energy efficiency: Specification and guidance, PAS 2035:2019, British Standards Institution, London. 